\title{
The Influence of Self-Efficacy on Chinese English Major's Oral Learning Strategies
}

\author{
Ke Zhang \\ School of Foreign Language, Yangtze Normal University, Chongqing, China \\ Email: 18325010991@163.com
}

How to cite this paper: Zhang, K. (2018) The Influence of Self-Efficacy on Chinese English Major's Oral Learning Strategies. Advances in Literary Study, 6, 62-68. https://doi.org/10.4236/als.2018.62007

Received: March 14, 2018

Accepted: April 16, 2018

Published: April 19, 2018

Copyright (C) 2018 by author and Scientific Research Publishing Inc. This work is licensed under the Creative Commons Attribution International License (CC BY 4.0).

http://creativecommons.org/licenses/by/4.0/

\begin{abstract}
The study aims to solve two problems: 1) The current situation of English majors in oral English study. 2) The influence and relevance of self-efficacy on oral English learning strategies of English majors in China. The study makes a comprehensive survey on the self-efficacy and oral learning strategies of English majors in Yangtze Normal University. It intends to make an investigation about English majors' self-efficacy and spoken English learning strategies, guiding English majors to learn how to make use of self-efficacy to solve the difficulties in oral learning and to improve oral communication ability.
\end{abstract}

\section{Keywords}

Self-Efficacy, English Majors, Oral Learning Strategies, Oral Proficiency, Gender

\section{Introduction}

Under the background of economic globalization, China has a huge demand of English major with professional talents in the current, and fluent spoken English is a basic requirement of English professional talents. Since the country began to emphasize the cultivation of high-quality talents, increasing number of people have been focusing on the English and oral English level of the overall college students, but paying little attention to the current situation of the oral study in English majors. There is nearly no relative study about English majors to search in China National Knowledge Infrastructure with the key words of oral English learning strategy. Most papers tend to study non-English major college students or high school students. As a member of English majors, I am deeply involved in this group and find many problems in the oral English learning of many English majors, especially the difficulties encountered to improve their oral ability.

Based on this situation, our research carried out. This study combines the 
self-efficacy with the oral learning strategy, and analyzes the students' learning situation with the theory, which is more appropriate and persuasive.

Since the 1980s, the relationship between self-efficacy and academic performance has been studied extensively. Bandura defined perceived self-efficacy as “... people's judgments of their capabilities to organize and execute courses of action required attaining designated types of performances" (Bandura, 1986). Recent studies have shown that learning self-efficacy is a motivation to students' learning effect, and it can adjust and control the students' learning activities. On the one hand, learning self-efficacy makes a difference in students' school choice; and on the other hand, it also affects students' learning perseverance, degree of efforts, self-monitoring learning and the use of learning strategies, thus influences the students' the completion of tasks of schoolwork (Pokay \& Blumenfeld, 1990; Pajares \& Kranzler, 1995; Pajares, 1996).

\section{Methods}

\subsection{Questionnaire Survey}

This study is mainly based on the combination of qualitative and quantitative research. First of all, a questionnaire survey is conducted to investigate the influence of self-efficacy on oral English learning strategies in English Majors of Yangtze Normal University. The study uses self-efficacy scale and self-made questionnaire containing 58 questions. Each question is scored by 5 points scale, and the answer options range from 1 to 5 , which included five items which are totally inconsistent with my situation in sequence. The questionnaire survey includes the following three parts:

1) Background information: collecting the student's personal information, including the sex, and the ability to speak English from their first year in the university to the present.

2) The general self-efficacy scale: It is made by a German psychologist, a total of 10 questions, five-point scale scoring by each question, in turn from totally inconsistent with my situation to fully comply with my situation, and high scores indicate that the students' learning of English is influenced by a strong sense of self-efficacy.

3) English learning strategies: oral English learning strategy questionnaire is based on "strategy inventory for language learning". According to the characteristics of Chinese students, we choose this questionnaire to investigate them. The questionnaire contains several English learning strategies such as affective strategies, compensation strategies, memory strategies, social strategies, etc.

\subsection{Survey Implementation Plan}

This survey was launched in December 2017, conducted a questionnaire in the English class. The questionnaires were distributed to the students, and teachers explain the function of the survey is to provide material support to a scientific research. The result of completing the questionnaire would not affect their 
learning and life. The accuracy of the scientific research and the authenticity are affected by their answers, so we hope the students fill the questionnaire with their own specific conditions, which is of benefit to collect real and effective information. After the students completed the test, we collected the questionnaire, and carried out the related data analysis. Ultimately, according to students' answers, we can get research on the self-efficacy and the oral English learning strategy.

\section{Findings}

\subsection{Reliability and Stability of the Questionnaire}

In order to guarantee the reliability and stability of the questionnaire, we must analyze the reliability of the questionnaire. When we collect data, using the same scale, may lead the results obtained to be similar, thus the reliability of the test is the test of the questionnaire with similarity. We usually measure the reliability of the questionnaire by using the coefficient of alpha (i.e., Cronbach's coefficient). The larger the coefficient of measurement, the higher the reliability and stability of the questionnaire. With the deepening of the research, scholars are increasingly demanding the reliability of the questionnaire, early studies of alpha coefficients above 0.5 reliability acceptable questionnaire, questionnaire for alpha coefficient is greater than 0.7 the questionnaire for the reliability of the questionnaire, recent research will alpha coefficient 0.6 as the questionnaire reliability in acceptable boundaries, even when the alpha coefficient is greater than 0.8 or is greater than 0.9 , which means that the questionnaire has high reliability. It can be seen from Table 1 , that the reliability analysis on reliability coefficient of each dimension are $0.869,0.817,0.878,0.821,0.877,0.911,0.877$, and questionnaire overall reliability coefficient is 0.965 . All of these are greater than 0.8 , indicating that the questionnaire has high reliability.

\subsection{Validity of the Questionnaire}

Validity analysis is a powerful tool to measure the degree of function that the

Table 1. Reliability statistics.

\begin{tabular}{ccc}
\hline & Clonbach Alpha & Numbers \\
\hline GESE & 0.869 & 10 \\
MEMS & 0.817 & 4 \\
COGS & 0.878 & 8 \\
COMS & 0.821 & 8 \\
METS & 0.877 & 10 \\
AFFS & 0.911 & 10 \\
SOCS & 0.853 & 5 \\
TOTAL & 0.965 & 55 \\
\hline
\end{tabular}


institute wants to measure. In this study, factor analysis method is used to test the validity of measurement. First, the KMO sample adequacy measurement and Bartlett sphere test are used to testify whether the data could be analyzed by factors. It can be seen from Table 2 that: KMO 0.822, between 0.5 and 0.9 , shows that there are common factors between variables and Bartlett's Test of Sphericity of Sig. 0.000 , less than 0.05 , so the questionnaire table total factor analysis is valid.

\subsection{Variation Analysis}

As can be seen from Table 3 and Table 4, T test (all known as independent sample $t$ test) is used to study the difference of gender in all dimensions. From the above table, it can be seen that different gender samples show significant difference in self-efficacy $(P<0.05)$, which means that different gender samples have differences in self-efficacy.

Specific analysis: Gender for self-efficacy showed 0.05 levels of significance ( $\mathrm{t}$ $=2.44, P=2.44$ ), as well as specific comparison difference, men's average (22.22), will be significantly lower than the average (26.61) in women. It can be seen from the conclusion that different gender samples show significant differences in

Table 2. KMO and Bartlett test.

\begin{tabular}{ccc}
\hline \multicolumn{2}{c}{ KMO sampling adequacy. } & 0.760 \\
\hline & Approximate chi-square & 4051.876 \\
Bartlett test of sphericity. & Degrees of freedom & 1485 \\
& Conspicuousness & 0.000 \\
\hline
\end{tabular}

Table 3. T test.

\begin{tabular}{|c|c|c|c|c|c|}
\hline & Sex & $\mathrm{N}$ & MEANS & Std. Deviation & Std. Error Mean \\
\hline \multirow{2}{*}{ GESE } & Male & 9 & 22.2222 & 3.15348 & 1.05116 \\
\hline & Female & 76 & 26.6053 & 5.25377 & 0.60265 \\
\hline \multirow{2}{*}{ MEMS } & Male & 9 & 9.0000 & 3.00000 & 1.00000 \\
\hline & Female & 76 & 9.9079 & 2.76250 & 0.31688 \\
\hline \multirow{2}{*}{ COGS } & Male & 9 & 19.4444 & 6.52133 & 2.17378 \\
\hline & Female & 76 & 20.7763 & 4.83763 & 0.55491 \\
\hline \multirow{2}{*}{ COMS } & Male & 9 & 18.4444 & 5.17472 & 1.72491 \\
\hline & Female & 76 & 21.1184 & 4.37864 & 0.50226 \\
\hline \multirow{2}{*}{ METS } & Male & 9 & 23.7778 & 6.22049 & 2.07350 \\
\hline & Female & 76 & 25.6316 & 5.91009 & 0.67793 \\
\hline \multirow{2}{*}{ AFFS } & Male & 9 & 28.4444 & 11.05793 & 3.68598 \\
\hline & Female & 76 & 28.4605 & 6.86331 & 0.78728 \\
\hline \multirow{2}{*}{ SOCS } & Male & 9 & 14.0000 & 4.87340 & 1.62447 \\
\hline & Female & 76 & 13.5395 & 3.88309 & 0.44542 \\
\hline
\end{tabular}


Table 4. Independent sample test.

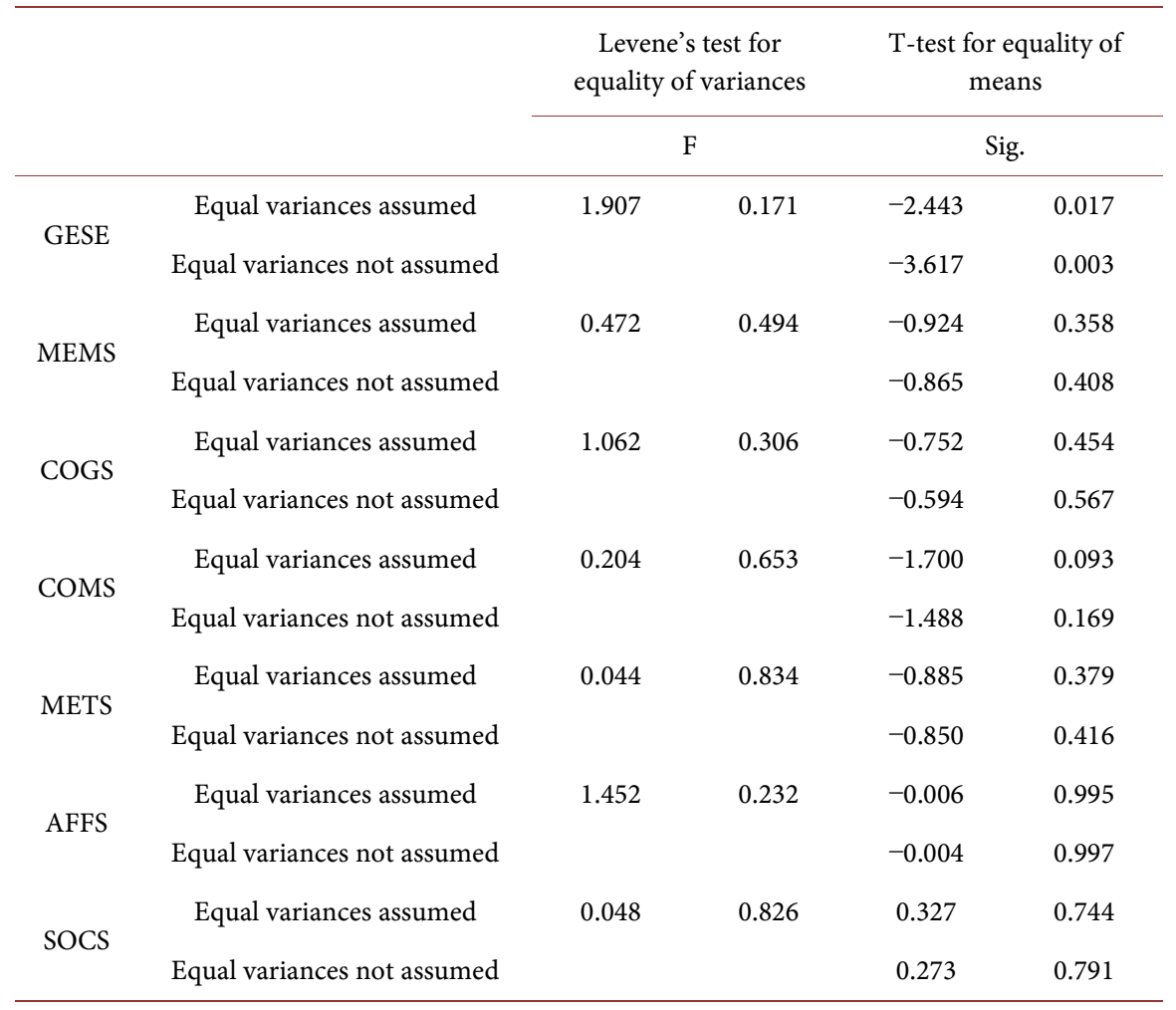

self-efficacy. In addition, the different gender samples show no significant difference in the remaining six dimensions ( $P$ BBB 00.05 ), which means that different gender samples show consistent consistency for the rest, and there is no difference.

\section{Conclusions and Suggestions}

\subsection{Conclusions}

It can be seen from the above tables that there are differences in self-efficacy between different genders, and there is no significant difference in the use of oral learning strategies. The data show that girls have higher self-efficacy than boys. According to the survey data, $42.86 \%$ of boys think that their oral English has not improved after entering university, and the other $42.86 \%$ of boys think their spoken English has improved a little after entering college. Only $14.26 \%$ of boys think their spoken English has improved a lot after entering college. 13.33\% of the girls believe that their oral English has not improved after attending university. $69.33 \%$ of the girls think their oral English has improved a little after attending university, while $17.26 \%$ of them think that their oral English has improved a lot after attending college. Therefore, we can conclude that the self-efficacy of female students is slightly higher than that of male students. And girls perform better than boys in oral study.

The oral learning situation of English majors in Yangtze Normal University is not very good. We can also see their spoken English in daily life and study. 
There are not many students who are willing to express their opinions actively in English teaching, and some students even cannot express themselves fluently in English when they are asked to express their views. In the school's English corner activities, some people tend to shy away when they were asked to express their opinions in front of foreign teachers. This is due to lack of confidence due to poor spoken English. In all the tested students, the number of students who think that their oral English has improved a lot account for only sixteen point six seven percent of the total number of participants, and the number of those who think their oral English has not improved accounts for fifteen point four eight percent. The result can be attributed to the lack of emphasis on oral English learning in schools and students' false cognition.

\subsection{Suggestions}

For English majors, it is necessary for the school to offer them oral English courses at least two or three years. In the opinion of most students, the function of English is only for examination. The excessive emphasis on vocabulary and the correct application of language knowledge in teaching also lead to the low communication ability of students. In the context of education, Chinese students pay more attention to the written application of English; they nearly neglect spoken English when they are in middle school and high school. So college teachers should make up for the shortage of English majors and improve their oral English in university. To offer the phonetic courses for two or three years not only increases students' phonetic knowledge, but also corrects their wrong pronunciation, and helps develop their ability in self-study and improve their other English skills. What's more, it is indispensable to arouse students' attention to oral English learning. In the aspect of verbal learning strategies, students are more likely to use affective strategies and metacognitive strategies. Research data show that oral learning strategies can help students learn more efficiently. However, in daily study, students are hardly aware of the classification and the composition of oral English learning strategies, and few people can consciously use the oral learning strategy to make efficient learning. Therefore, in the course of teaching, teachers can consciously teach students the concept of oral English learning strategies, and help them find appropriate learning methods to improve their learning efficiency. In addition, in the courses of oral English teaching, teachers need to explore a variety of teaching modes, and improve the self-efficacy of students in oral study through the guidance and testing of the front and side.

\section{References}

Bandura, A. (1986). Social Foundations of Thought and Action: A Social Cognitive Theory. Prentice-Hall.

Pajares, F. (1996). Self-Efficacy Beliefs and Mathematical Problem Solving of Gifted Students. Contemporary Educational Psychology, 21, 325-344.

https://doi.org/10.1006/ceps.1996.0025

Pajares, F., \& Kranzler, J. (1995). Self-Efficacy Beliefs and General Mental Ability in Ma- 
thematical Problem-Solving. Contemporary Educational Psychology, 20, 426-443.

https://doi.org/10.1006/ceps.1995.1029

Pokay, P., \& Blumenfeld, P. C. (1990). Predicting Achievement Early and Late in the Semester: The Role of Motivation and Use of Learning Strategies. Journal of Educational Psychology, 82, 41-50. https://doi.org/10.1037/0022-0663.82.1.41 